\title{
Gonadotropin Releasing Hormone Agonists Have an Anti-apoptotic Effect on Cumulus Cells
}

\author{
Paola Scaruffi ${ }^{1,+}$, Sara Stigliani ${ }^{1,+}$, Barbara Cardinali ${ }^{2}$, Claudia Massarotti $^{3}$, \\ Matteo Lambertini ${ }^{4,5, * \mathbb{D}}$, Fausta Sozzi ${ }^{1}$, Chiara Dellepiane ${ }^{2}$, Domenico Franco Merlo ${ }^{6}$, \\ Paola Anserini ${ }^{1}{ }^{1(1)}$ and Lucia Del Mastro ${ }^{2,4}$ \\ 1 UOS Physiopathology of Human Reproduction, IRCCS Ospedale Policlinico San Martino, 16132 Genoa, \\ Italy; paola.scaruffi@hsanmartino.it (P.S.); sara.stigliani@hsanmartino.it (S.S.); \\ fausta.sozzi@hsanmartino.it (F.S.); paola.anserini@hsanmartino.it (P.A.) \\ 2 Breast Unit, IRCCS Ospedale Policlinico San Martino, 16132 Genoa, Italy; \\ barbara.cardinali@hsanmartino.it (B.C.); chiara.delle@hotmail.it (C.D.); \\ lucia.delmastro@hsanmartino.it (L.D.M.) \\ 3 Department of Neurosciences, Rehabilitation, Ophthalmology, Genetics, Maternal and Child Health, \\ University of Genoa, 16132 Genoa, Italy; claudia.massarotti@gmail.com \\ 4 Department of Internal Medicine, University of Genoa, 16132 Genoa, Italy \\ 5 U.O.C. Clinica di Oncologia Medica, IRCCS Ospedale Policlinico San Martino, 16132 Genoa, Italy \\ 6 Infrastruttura Ricerca e Statistica, Azienda Unità Sanitaria Locale-IRCCS di Reggio Emilia, 42123 Reggio \\ Emilia, Italy; domenico.merlo@ausl.re.it \\ * Correspondence: matteo.lambertini@unige.it; Tel.: +39-010-555-4254 \\ + These authors contributed equally to this work.
}

Received: 30 October 2019; Accepted: 25 November 2019; Published: 30 November 2019

\begin{abstract}
Background: Ovaries are sensitive to chemotherapy, which may lead to early depletion of primordial follicle reserve. One strategy for gonadal function preservation is temporary ovarian suppression with Gonadotropin Releasing Hormone agonists (GnRHa) during chemotherapy. To date, GnRHa protective mechanism of action remains not fully elucidated. Methods: We collected 260 immature cumulus cell-oocyte complexes (COC) from 111 women $<38$ years old, with a normal ovarian reserve. The $\mathrm{COC}$ were randomly assigned to the following groups: (a) control; culture with the addition of (b) GnRHa; (c) cyclophosphamide; (d) cyclophosphamide plus GnRHa. After in vitro treatments, RNA and proteins were extracted from oocytes and cumulus cells (CC), separately. Potential effects of drugs were evaluated on GnRH receptors, apoptosis pathways, ceramide pathway, and glutathione synthesis by quantitative PCR and, whenever possible, by Western blot. Results: Cyclophosphamide triggered activation of the extrinsic pathway of apoptosis mediated by BAX in CC. The co-administration of GnRHa inhibited the apoptosis pathway in CC. According to our model, the GnRHa does not directly act on oocytes, which do not express GnRH receptors. Moreover, glutathione synthesis was decreased after GnRHa treatment both in CC and oocytes. Conclusion: Our data suggest that the protective mechanisms induced by GnRHa is mediated by an anti-apoptotic effect on CC.
\end{abstract}

Keywords: cyclophosphamide; GnRH agonist; apoptosis; oocytes; human cumulus cell-oocyte complexes

\section{Introduction}

Young women with cancer or non-malignant diseases requiring treatment with cytotoxic chemotherapy are candidates for fertility preservation. The ovarian reserve is constituted by a fixed number of resting primordial follicles present at birth that are slowly depleted throughout 
a woman's reproductive life [1]. The ovaries are very sensitive to cytotoxic chemotherapy agents; they can induce apoptotic death of the oocytes and the surrounding granulosa cells (GC), leading to irreversible early depletion of the primordial follicle reserve [2-4]. Therefore, in young females, chemotherapy can induce premature ovarian insufficiency and infertility [5].

Strategies for preservation of female gonadal function and/or fertility include temporary ovarian suppression with Gonadotropin Releasing Hormone agonists (GnRHa), oocyte/embryo or ovarian tissue cryopreservation [6,7]. In comparison with cryopreservation strategies, temporary ovarian suppression with GnRHa during chemotherapy has been developed specifically, as a technique to protect the ovaries from the gonadotoxic effect of cytotoxic systemic therapy. In addition, the main advantages are that it is simple to administer, less invasive and expensive, and does not require delay in initiating anticancer therapies. Important novel research efforts in the field have elucidated the efficacy and safety of this option, and it is now endorsed for clinical use by several guidelines [6-9]. Nevertheless, the performance of this strategy remains still debated [10]. Firstly, while consistent data proved the efficacy of the use of temporary ovarian suppression with GnRHa during chemotherapy in breast cancer patients [11], negative results were obtained in trials conducted in women with tumors other than breast cancer (i.e., hematological malignancies) [12,13]. Secondly, in terms of fertility preservation potential of GnRHa use during chemotherapy, available data are limited. The most recent meta-analyses have shown a significantly higher post-treatment pregnancy rate for premenopausal breast cancer patients treated with GnRHa during chemotherapy, as compared to those treated with cytotoxic therapy alone $[8,9,11,13-16]$, without benefit in lymphoma patients $[12,13]$. Thirdly, concerning experimental preclinical data, the potential mechanisms of action for the protective effects of GnRHa during chemotherapy remains not fully clarified. Several experimental studies have been conducted in both female mice and rats. The majority of the studies showed a positive effect for GnRHa treatment in preventing chemotherapy-induced depletion of primordial follicles [17-25]. However, other studies did not confirm these findings [26-29]. Importantly, very limited experimental preclinical data are available in female primates and human models [30-32].

In regard to the activated pathway, stimulation of mouse granulosa cells with GnRHa did not induce a detectable rise in cAMP levels $[27,33]$. However, a recent study reported increased cAMP levels in human cortical pieces and in granulosa cell lines following GnRHa stimulation [32], thus suggesting potential different actions of GnRHa in rodents and humans. Therefore, further investigation in human models are needed because of crucial importance considering the already available clinical use for this strategy.

Hereby, we studied immature cell-oocyte complexes (COC) discarded from in vitro fertilization cycles in healthy women to investigate whether GnRHa was able to protect the oocytes from cyclophosphamide toxicity. Although chemotherapy damages primordial follicle oocytes, this was the only strategy available to us for treatment of ex vivo human COC, the major anatomic and functional unit of the ovary. The COC were cultured without the addition of drugs, in the presence of cyclophosphamide alone or GnRHa alone or both drugs. Effects of these treatments were evaluated on GnRH receptors, apoptosis pathways, ceramide pathway, and glutathione synthesis. Data were collected on both oocytes and cumulus cells (CC) by gene expression analysis.

\section{Results}

\subsection{GnRH Receptors}

In CC, only the GnRHR-I gene was detectable and its expression level was not modulated by treatment. In the oocytes, neither GnRHR-I nor GnRHR-II genes were expressed or induced by chemotherapy and GnRHa. 


\subsection{Apoptosis Pathway}

In CC, BAK1, BCL2L10, FASL, and TP63 pro-apoptotic genes were not expressed. Figure 1 shows expression profiles of the expressed pro-apoptotic genes in CC.

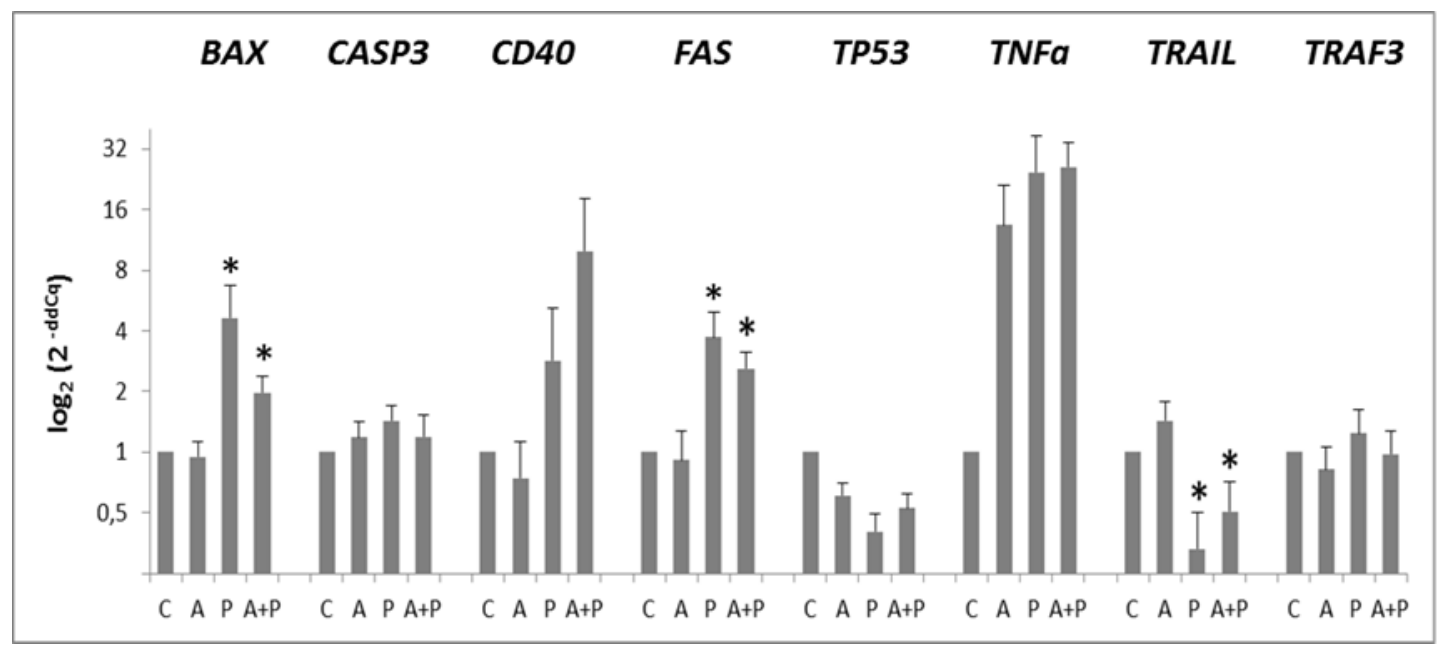

Figure 1. Expression levels of $B A X, C A S P 3, C D 40, F A S, T P 53, T N F \alpha, T R A I L, T R A F 3$ pro-apoptotic genes in $C C$ of cell-oocyte complexes (COC) cultured without the addition of drugs (control, $\mathrm{C}$ ), treated with GnRHa (A), phosphoramide mustard (P), and GnRHa+phosphoramide mustard (A+P). Results are expressed as $\log _{2}\left(2^{-\mathrm{ddCq}}\right)$ values using HPRT1 as reference gene and $\mathrm{C}$ group as calibrator. Error bars denote standard error. *: $p$ value $<0.05$ in $\mathrm{P}$ and $\mathrm{A}+\mathrm{P}$ versus A group.

The expression of TP53 was not modified by any treatment. Expression levels of BAX, CASP3, $F A S$, and TRAF3 were increased in $P$ group as compared to $C$ group and they were diminished after GnRHa treatment. Such a behavior was particularly evident for $B A X$ and $F A S$ genes, that, compared to A group, were significantly up-regulated both in $\mathrm{P}(p=0.0152$ and $p=0.0006$, respectively) and in $\mathrm{A}+\mathrm{P}$ group ( $p=0.0015$ and $p=0.0006$, respectively). A trend of decreasing expression of BAX and FAS was observed in $\mathrm{A}+\mathrm{P}$ group than in the $\mathrm{P}$ one. Western Blotting analysis of BAX showed the presence of BAX 21KDa (putatively BAX $\alpha$, the most common form of BAX [34]) and BAX 18KDa that could be the BAX cleaved product (Figure 2).

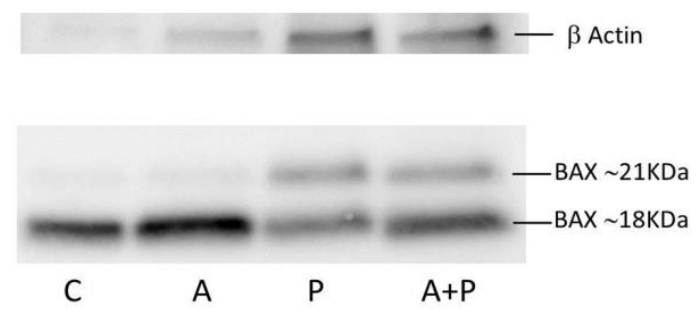

Figure 2. Western blot analysis of BAX in CC of COC cultured without the addition of drugs (control group, C), treated with GnRHa (A), phosphoramide mustard (P), and GnRHa+phosphoramide mustard $(\mathrm{A}+\mathrm{P})$. The rabbit polyclonal anti-BAX antibody was diluted 1:1000.

The expression level of BAX 21 KDa seems to increase in $\mathrm{P}$ compared to $\mathrm{C}$ and $\mathrm{A}$ groups, and to diminish in $\mathrm{A}+\mathrm{P}$ group with respect to $\mathrm{P}$ group. Moreover, the ratio between $\mathrm{BAX} \sim 21 \mathrm{KDa}$ and BAX 18 KDa tends to increase following chemotherapy treatment, suggesting that cyclophosphamide may promote the synthesis of BAX 21 KDa. Due to the low amount of material and the difference in protein loading because of interfering in quantification due to Human Serum Albumin (HSA) in IVF medium, these results should only be interpreted qualitatively. 
A trend for increased expression of CD40 and TNF $\alpha$ was observed moving from $\mathrm{A}$ to $\mathrm{P}$ and $\mathrm{A}+\mathrm{P}$ treatments. A statistically significant reduction of TRAIL expression was observed in the $\mathrm{P}$ and $\mathrm{A}+\mathrm{P}$ group, as compared to A group ( $p=0.0005$ and $p=0.0015$, respectively).

In CC, all anti-apoptotic genes were expressed, with the exception of BIRC5 (Figure 3). Expression of $B C L 2$ gene was significantly modified by the different treatments: its expression was reduced in $P$ group $(p=0.0256)$ and increased in $\mathrm{A}+\mathrm{P}$ group $(p=0.0087)$. On the other hand, BAG3 and TRAF2 expression was increased in $\mathrm{P}$ group and slightly diminished in $\mathrm{A}+\mathrm{P}$ group, without reaching statistical significance. Expression of CFLAR was not modified by any treatment.

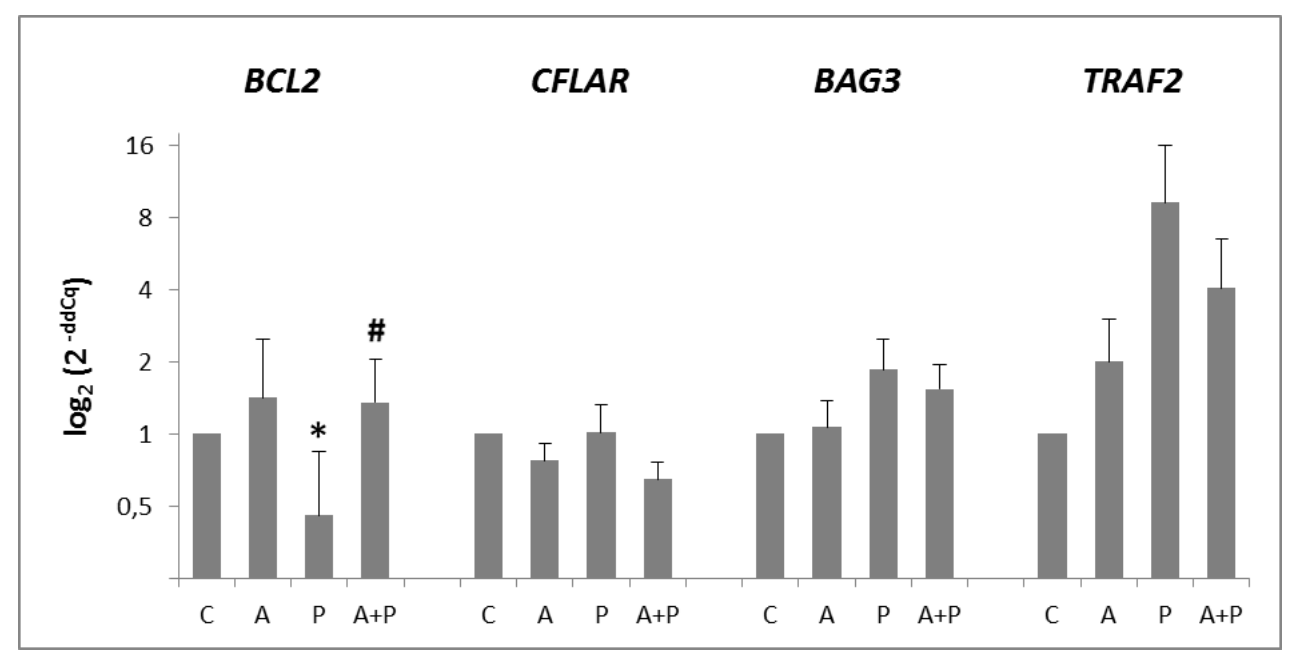

Figure 3. Expression levels of $B C L 2, C F L A R, B A G 3$, and TRAF2 anti-apoptotic genes in CC of COC cultured without the addition of drugs (control, C), treated with GnRHa (A), phosphoramide mustard $(\mathrm{P})$, and $\mathrm{GnRHa}+$ phosphoramide mustard $(\mathrm{A}+\mathrm{P})$. Results are expressed as $\log _{2}\left(2^{\text {-ddCq }}\right)$ values using HPRT1, as a reference gene and the $C$ group as a calibrator. Error bars denote standard error. *: $p$ value $<0.05$ in A group versus $\mathrm{P}$ group; \#: $p$ value $<0.05$ in $\mathrm{P}$ group versus $\mathrm{A}+\mathrm{P}$ group.

In oocytes, BAK1, CD40, FASL, TNF $\alpha$, and TRAIL pro-apoptotic genes were not expressed. The levels of $B A X$ and $B C L 2 L 10$ mRNAs were not modified by any treatment. The expression of CASP3, TP53, TP63, and TRAF3 was heterogeneously modulated by all the administered drugs (Supplementary Figure S1A). FAS gene was not evaluable because of its high variability among the replicates. All anti-apoptotic genes were expressed in the oocytes with the exception of $B C L 2$ that was detected only in the C group. The expression of BIRC5, CFLAR, BAG3, and TRAF2 was not significantly modulated by treatments (Supplementary Figure S1B).

\subsection{Sphingomyelin Pathway}

The CC expressed all sphingomyelin pathway genes, whereas in the oocytes, SPHK1 was not detected. The changes in genes of ceramide-sphingosine pathway were not statistically significant (Supplementary Figure S2), which unfortunately indicates inadequate quantity of the investigated material.

\subsection{Glutathione-Mediated Pathway}

The GCLM gene was expressed in both the CC (Figure 4A) and the oocytes (Figure 4B). Its expression was significantly higher in the P group, as compared to the A group in CC and oocytes ( $p$ $=0.0191$ and $p=0.0421$, respectively). In the $\mathrm{A}+\mathrm{P}$ group, a significant reduction of GCLM level was observed in both CC ( $p=0.0191)$ and oocytes $(p=0.0171)$ compared to the P group. 


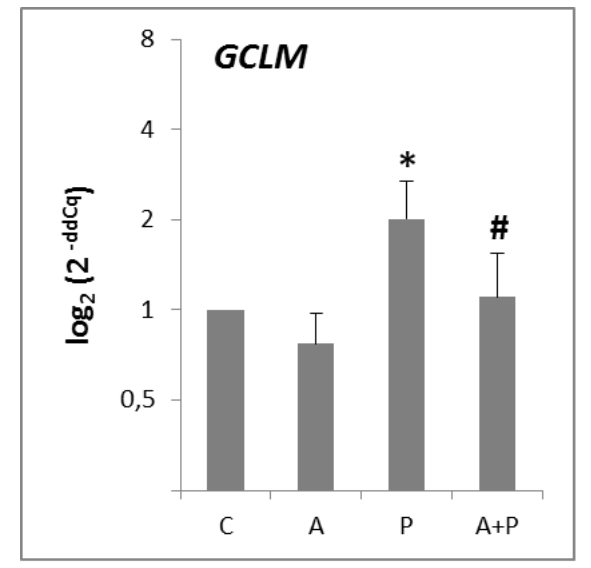

(A)

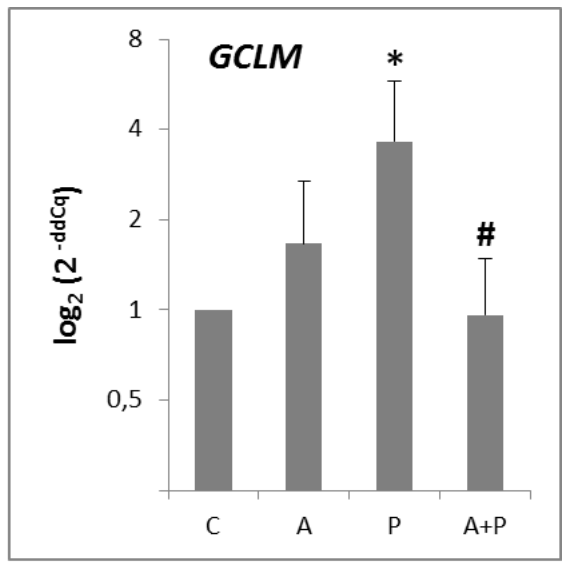

(B)

Figure 4. (A) Expression levels of GCLM gene in CC of COC cultured without the addition of drugs (control, C), treated with GnRHa (A), phosphoramide mustard (P), and GnRHa+phosphoramide mustard $(\mathrm{A}+\mathrm{P})$; (B) Expression levels of GCLM gene in oocytes of COC cultured without the addition of drugs (control, C), treated with GnRHa (A), phosphoramide mustard (P), and GnRHa+phosphoramide mustard $(\mathrm{A}+\mathrm{P})$. Results are expressed as $\log _{2}\left(2^{-\mathrm{ddCq}}\right)$ values using HPRT1 as reference gene and $\mathrm{C}$ group as calibrator. Error bars denote standard error. *: $p$ value $<0.05$ in A group versus P group; \#: $p$ value $<0.05$ in $\mathrm{P}$ group versus AP group.

\section{Discussion}

To date, the potential protective mechanism of action of temporary ovarian suppression with GnRHa during chemotherapy is highly debated and remains not clearly elucidated. Potential hypothesized mechanisms include [10,35-37]: (i) interruption of Follicle-Stimulating Hormone secretion determining a hypo-gonadotropic milieu, in which follicular recruitment is inhibited and fewer primordial follicles attain the chemotherapy-sensitive stages of proliferation and follicle maturation; (ii) decrease in utero-ovarian perfusion due to the hypo-estrogenic state generated by pituitary-gonadal desensitization; (iii) activation of GnRH receptors; (iv) up-regulation of intra-gonadal anti-apoptotic molecules; or (v) protection of undifferentiated germ line stem cells. However, so far, none of these hypotheses has been definitively demonstrated. With the exception of three reports (one using ex-vivo and in vitro human cells [32] and two a mouse model [26,27]), the majority of in vivo $[19,20,24,29,30,38-42]$ and in vitro $[29,31,43]$ studies showed that GnRHa maintains primordial follicles and inhibit chemotherapy-induced apoptosis. So far, only three reports on the molecular mechanisms of function of GnRHa on cells/tissue of human origin (namely, ovarian cancer cells [43], granulosa GC [31], ex vivo and in vitro models of ovary and GC [32]) are available.

The novelty of our work lies in studying human, ex vivo COC. Indeed, we treated the COC and then analyzed the effect of GnRHa and cyclophosphamide in the oocyte and CC compartments, separately. Such an experimental set-up allowed us to closely simulate the physiological microenvironment, since $\mathrm{COC}$ is a fundamental anatomic and functional unit of the ovarian tissue, and oocyte growth and competence are dependent on bidirectional communication between the oocyte and the CC [44,45]. We adopted a culture system on the bases of experience from IVF. First, we used a bicarbonate buffered culture medium designed for the incubation of oocytes, supplemented with HSA, gentamicin, antioxidants, non-essential amino acids, and glucose for efficient COC survival. Second, COC incubation was performed in a controlled atmosphere with low oxygen tension (5\%), in order to closely mimic conditions of the natural female environment since in the human uterus, the oxygen tension ranges between $2-8 \%$ [46]. Such a hypoxic culture reduces the generation of reactive oxygen species and related damage to oocytes [47]. 
Our experiments on COC showed that cyclophosphamide was mainly detrimental to the CC compartment. In fact, chemotherapy started a series of molecular signals to trigger apoptosis through the extrinsic pathway activation [48]. Specifically, in CC, the cyclophosphamide-mediated death signal seemed to be transmitted from the cell surface to the intracellular signaling effectors mainly by involvement of $F A S$, and marginally by $C D 40, T R A F 3$ and TNF $\alpha$, all members of the tumor necrosis factor receptor gene superfamily [49]. The CC commitment to apoptosis was mediated by the anti-apoptotic $B C L 2$ and the pro-apoptotic $B A X$ genes [50], whose expression was down- and up-regulated after chemotherapy, respectively. At the protein level, we observed the presence of BAX 18KDa that may reflect a cellular stress due to the extended culture. Intriguingly, the trend for increased $\mathrm{BAX} \sim 21 \mathrm{KDa}$ to $\mathrm{BAX} \sim 18 \mathrm{KDa}$ ratio observed following chemotherapy suggests that cyclophosphamide may promote synthesis of BAX 21KDa that in turn, may trigger the activation of apoptosis. This effect seems to be partially counteracted by GnRHa.

Finally, the trend of CASP3 up-regulation in CC treated with cyclophosphamide suggested that caspase- 3 may be one of the "executioner" caspases activated at the end of the process. The resulting cell death was displayed by the morphological changes observed in CC in response to cyclophosphamide.

The administration of GnRHa before cyclophosphamide tended to down-regulate expression of pro-apoptotic genes as $F A S, T R A F 3, B A X, C A S P 3$, and up-regulate transcription of anti-apoptotic $B C L 2$ in CC. Our molecular data did not demonstrate a direct GnRHa-mediated protection against the cytotoxic effects of cyclophosphamide in the oocytes. In fact, we observed a morphological rescue of the oocytes without any significant modulation of the analyzed genes when chemotherapy was combined with GnRHa. Taken together, these results suggest that the co-administration of GnRHa with chemotherapy inhibited the extrinsic apoptotic signaling pathway in CC only, whereas it did not impact on the oocytes. In other words, oocytes may survive the detrimental effect of cyclophosphamide thanks to the protective role of the surrounding GC. Moreover, we demonstrated at molecular level that GnRHa directly targets the CC, since the GnRHR-I gene was detectable only in these cells without any evident modulation by treatments. This finding in our model is in agreement with a previous report showing that GnRH receptors are mainly expressed by proliferating and luteinized GC of the growing follicles and corpus luteum, respectively [51].

Finally, the investigation of the first rate-limiting enzyme of glutathione synthesis [52] showed that in both CC and oocytes, glutathione synthesis was induced by cyclophosphamide. This is in line with prior evidence suggesting that glutathione is an important intracellular antioxidant playing several vital roles in the cells such as anti-oxidation and detoxification of xenobiotics [53]. Specifically, in the metabolism-dependent toxicity of chemotherapy, the glutathione has a role in binding phosphoramide mustard and acrolein, two toxic and highly reactive metabolites. The resulting sulfhydryl-containing compounds protect against toxicity of these alkylating agents and at the same time do not interfere with the chemotherapeutic activity of cyclophosphamide [54]. Consistently with the protective effect of GnRHa, and thus the reduced need of a detoxifying system, we observed a decrease of GCLM in CC and in oocytes after GnRHa treatment.

Although the expression of investigated targets was detected at low levels because of paucity of RNAs and proteins due to the nature of our COC model, we hypothesize that GnRHa directly may act on CC to protect the oocytes from cyclophosphamide toxicity by an anti-apoptotic effect. It is noteworthy that the protective role of GnRHa against cyclophosphamide has been recently excluded in ex vivo and in vitro models of human ovary and GC [32]. We believe that the opposite conclusions may be due both to the different timing of drugs administration and to the different dose of GnRHa used for experiments. In fact, in Bildik's model, GnRHa was administered to cells at the same time as chemotherapy or $1-2 \mathrm{~h}$ prior to cyclophosphamide, whereas in $\mathrm{A}+\mathrm{P}$ group of our model the incubation with GnRHa was performed $24 \mathrm{~h}$ before the addiction of chemotherapy to COC. Such a GnRHa schedule better mimics the protocol used in the clinic with patients starting GnRHa at least 1 week before chemotherapy initiation [55]. Moreover, in Bildik's experiments the GnRHa was used at $10-20-40 \mathrm{nM}$, that is two order of magnitude lower than ours $(1 \mu \mathrm{M})$. Thus, we suggest that prior 
and longer exposure to a higher dose of GnRHa facilitates in CC, and indirectly in the oocytes, the activation of those molecular pathways that lead to decrease cell damage and follicular apoptosis during chemotherapy.

Our data suggest that the protective gonadal effect of GnRHa treatment during chemotherapy with cyclophosphamide may be indirect and mediated through the surrounding CC. Despite this being a preliminary study, it adds knowledge on the potential mechanisms of action for the protective effects of GnRHa during chemotherapy, a therapeutic strategy that is now endorsed for clinical use by several guidelines. In order to overcome the intrinsic limitation of the presented study in terms of transcript/proteome coverage, future wide analyses could complement our results by larger depth investigations of the precise molecular mechanisms [56,57].

\section{Materials and Methods}

\subsection{COC Collection}

Human immature COC, retrieved for assisted reproduction and discarded because they were not suitable for in vitro fertilization, were collected from 111 women between March 2014 to March 2017 by transvaginal oocyte aspiration $36 \mathrm{~h}$ after injection of human chorionic gonadotropin. All COC derived from women $<38$ years old (range: 22-38 years), with a normal ovarian reserve [58], without any ovarian pathology. A standard controlled ovarian stimulation protocol including gonadotropin administration in combination with GnRH antagonist was applied as previously described [59]. Under SZX7 stereomicroscope (Olympus Corporation, Tokyo, Japan), evaluation of COC maturity was based upon the expansion and radiance of the cumulus-corona complex, which surrounds the oocyte [60]. Absence of expanded cumulus-corona complex was associated with oocyte immaturity. Immature COC were incubated in Sydney IVF Fertilization medium (Cook Medical, Bloomington, IN, USA) at $37^{\circ} \mathrm{C}$ in a humidified atmosphere of $6 \% \mathrm{CO}_{2}, 5 \% \mathrm{O}_{2}$ using Galaxy $48 \mathrm{R}$ incubator (New Brunswick Scientific, Edison, NJ, USA). COC culture was performed in Nunc ${ }^{\mathrm{TM}} 4$-well IVF dishes (Thermo Fisher Scientific, Waltham, MA, USA).

\subsection{Ethical Approval}

Human immature COC, not suitable for IVF treatment, were donated after written informed consent. The study was approved by the Ethics Committee of Regione Liguria (approval n. 032REG2013, approved on November 12th, 2013).

\subsection{Study Design}

We treated whole COC and then analyzed the effect of GnRHa and cyclophosphamide in the oocyte and CC compartments, separately. The COC were randomly assigned to each treatment group using a computer-generated randomization list: (i) Control group (no drugs) (C); (ii) GnRHa-treated group (A); (iii) Chemotherapy-treated group (P); (iv) Chemotherapy plus GnRHa-treated group (A+P). A total of 260 COC were analyzed, we utilized 200 COC for gene expression analysis (five replicates of the four experimental groups, pools of 10 oocytes and relative CC), and $60 \mathrm{COC}$ for protein analysis (three replicates of the four experimental groups, pools of 5 oocytes and relative CC).

\subsection{In Vitro Treatments}

The control group was incubated for $48 \mathrm{~h}$ in the Sydney IVF Fertilization medium. At t0 in group A the GnRHa $(1 \mu \mathrm{M}$ triptorelin, the concentration that obtain the maximum protection effect according to Imai et al. [31]; Sigma-Aldrich S.r.l., Milan, Italy) was added, and incubation was performed for $48 \mathrm{~h}$. At $\mathrm{t} 0+24 \mathrm{~h}$ in group $\mathrm{P}$ the chemotherapy $(30 \mu \mathrm{M})$ was added and incubation was performed for 24 $\mathrm{h}$. We chose the chemotherapy dose by performing preliminary MTT assay on cumulus cells. At t0 in group $\mathrm{A}+\mathrm{P}$ the $\mathrm{GnRHa}(1 \mu \mathrm{M})$ was added, the incubation was performed for $24 \mathrm{~h}$, and then the chemotherapy $(30 \mu \mathrm{M})$ was added for additional $24 \mathrm{~h}$ of incubation. Phosphamide mustard was used 
as a chemotherapy agent considering it is the active metabolite of cyclophosphamide (Open Chemical Repository, Developmental Therapeutics Program, National Institutes of Health, Rockville, MD, USA).

\subsection{RNA Isolation, Quantitation and Retro-Transcription}

At the end of treatment, the oocytes were denuded of CC by enzymatic treatment with $80 \mathrm{IU} / \mathrm{mL}$ hyaluronidase solution (Origio, Målov, Denmark). Oocytes and CC were separately washed in Phosphate buffered saline (PBS), frozen in Qiazol (Qiagen, Hilden, Germany), and stored at $-80^{\circ} \mathrm{C}$. Pools of 10 oocytes and CC were used for molecular analyses separately. Total RNA was extracted from each pool using the miRNeasy Micro kit (Qiagen), according to the manufacturer's procedure. Quantification and quality control of total RNA were performed by RNA 6000 Pico kit on a 2100 Bioanalyzer (Agilent Technologies, Santa Clara, CA, USA). The RNA (2 ng or $10 \mathrm{ng}$ for oocytes and CC, respectively) was amplified and reverse-transcribed using Ovation Pico WTA System V2 (NuGEN, AC Leek, The Netherlands) following the manufacturer's instructions. cDNA was purified by Mini Elute kit (Qiagen) and diluted 1:10 for molecular analyses.

\subsection{Quantitative PCR ( $q P C R)$}

We investigated the following targets: (i) GnRH receptor genes (GnRHR-I and GnRHR-II); (ii) Pro-apoptotic (BAX, BAK, BCL2L10, CD40, TRAF3, TP53, TP63, CASP3, TNF- $\alpha$, FAS, FASL, and TRAIL) and anti-apoptotic (BCL2, BIRC5, CFLAR, BAG3, and TRAF2) genes; (iii) Sphingomyelin pathway: sphingomyelin phosphodiesterase 1 (SMPD1), ceramide synthase 1 (CERS1), $N$-acylsphingosine amidohydrolase 1 ( $A S A H 1$ ), and sphingosine-1-kinase (SPHK1) genes; (iv) glutamate-cysteine ligase (GCLM), the first rate limiting enzyme of glutathione synthesis. HPRT1 was used as reference gene. Specific TaqMan ${ }^{\circledR}$ assays were performed in triplicate in a Mastercycler epRealPlex2S system (Eppendorf, Hamburg, Germany). Negative control (water as template) was run simultaneously.

\subsection{Western Blot Analysis}

The CC were lysated in RIPA Buffer with $0.1 \mathrm{mM}$ Phenylmethanesulfonyl fluoride (PMSF, Cell Signaling Technology Danvers, MA, USA) and protease inhibitors (Sigma S.r.l.). The lysates were stored at $-20^{\circ} \mathrm{C}$. Protein amount was evaluated using Pierce ${ }^{\mathrm{TM}} 660 \mathrm{~nm}$ Protein Assay Reagent (Pierce Biotechnology, Rockford, IL, USA) and micro DC Protein Assay (Biorad Laboratories, Hercules, CA, USA). Proteins were resolved in 4-20\% SDS Mini Protean TGX Precast gels (Biorad) and transferred on a PVDF membrane using a Trans-Blot Turbo Trasfert System (Biorad). Membranes were blocked with $1 \%$ no fat milk in PBS containing $0.05 \%$ Tween 20 for $1 \mathrm{~h}$ and probed with rabbit polyclonal anti-BAX (Cell Signaling Technology) antibody overnight at $+4{ }^{\circ} \mathrm{C}$. Bound antibody was detected using horseradish peroxidase (HRP)-conjugated anti-rabbit secondary antibody (Cell Signaling Technology) incubated $1 \mathrm{~h}$ at room temperature. Proteins were detected by chemiluminescence (Clarity Western ECL Substrate, Biorad) using UVITEC Imaging System (Cleaver Scientific, Cambridge, UK). Quantification was performed after normalization on the $\beta$-actin band immunoassayed (HRP-conjugated $\beta$-Actin Rabbit monoclonal antibody, Cell Signaling Technology).

\subsection{Statistical Analysis}

RealPlex software v.2.0 (Eppendorf) was used to determine quantification cycle (Cq). Results of qPCR were expressed as relative values (ddCq method [61] using HPRT1 as reference gene [62]) and control group as calibrator). Mann-Whitney test (MedCalc ${ }^{\circledR}$ software, Mariakerke, Belgium) was used to test the significance of the difference between the sum of the ranks of each target gene measured in each treatment groups. Between treatment groups differences were considered statistically significant at a two-sided $p$-value $<0.05$.

Supplementary Materials: Supplementary Materials can be found at http://www.mdpi.com/1422-0067/20/23/ 6045/s1. 
Author Contributions: Conceptualization, P.S., S.S., B.C., P.A. and L.D.M.; Data curation, P.S., S.S. and B.C.; Formal analysis, D.F.M.; Funding acquisition, L.D.M.; Methodology, P.S., S.S. and B.C.; Resources, C.M., M.L., F.S., C.D. and P.A.; Writing—original draft, P.S.; Writing—review \& editing, P.S., S.S., B.C., C.M., M.L., F.S., C.D., D.F.M., P.A. and L.D.M.

Funding: This research was funded by AIRC (Associazione Italiana per la Ricerca sul Cancro) grant number IG 2013-14272.

Acknowledgments: We are grateful to patients who donated their immature COC. Sara Stigliani was an AIRC fellow. Matteo Lambertini acknowledges the support from the European Society for Medical Oncology (ESMO) for a Translational Research Fellowship at the Institut Jules Bordet in Brussels (Belgium).

Conflicts of Interest: The authors declare no conflict of interest. The funders had no role in the design of the study; in the collection, analyses, or interpretation of data; in the writing of the manuscript, or in the decision to publish the results.

$\begin{array}{ll}\text { Abbreviations } \\ \text { GnRHa } & \text { Gonadotropin Releasing Hormone agonists } \\ \text { COC } & \text { Cumulus cell-Oocyte Complexes } \\ \text { CC } & \text { Cumulus Cells } \\ \text { GC } & \text { Granulosa Cells } \\ \text { IVF } & \text { In Vitro Fertilization } \\ \text { HSA } & \text { Human Serum Albumin }\end{array}$

\section{References}

1. Wallace, W.H.; Kelsey, T.W. Human ovarian reserve from conception to the menopause. PLoS ONE 2010, 5 , e8772. [CrossRef] [PubMed]

2. Meirow, D.; Nugent, D. The effects of radiotherapy and chemotherapy on female reproduction. Hum. Reprod. Update 2001, 7, 535-543. [CrossRef] [PubMed]

3. Oktem, O.; Oktay, K. A novel ovarian xenografting model to characterize the impact of chemotherapy agents on human primordial follicle reserve. Cancer Res. 2007, 67, 10159-10162. [CrossRef] [PubMed]

4. Morgan, S.; Anderson, R.A.; Gourley, C.; Wallace, W.H.; Spears, N. How do chemotherapeutic agents damage the ovary? Hum. Reprod. Update 2012, 18, 525-535. [CrossRef]

5. Donnez, J.; Dolmans, M.M. Fertility Preservation in Women. N. Engl. J. Med. 2017, 377, 1657-1665. [CrossRef]

6. Lambertini, M.; Del Mastro, L.; Pescio, M.C.; Andersen, C.Y.; Azim, H.A.; Peccatori, F.A.; Costa, M.; Revelli, A.; Salvagno, F.; Gennari, A.; et al. Cancer and fertility preservation: International recommendations from an expert meeting. BMC Med. 2016, 14, 1. [CrossRef]

7. Lambertini, M.; Cinquini, M.; Moschetti, I.; Peccatori, F.A.; Anserini, P.; Valenzano Menada, M.; Tomirotti, M.; Del Mastro, L. Temporary ovarian suppression during chemotherapy to preserve ovarian function and fertility in breast cancer patients: A GRADE approach for evidence evaluation and recommendations by the Italian Association of Medical Oncology. Eur. J. Cancer 2017, 71, 25-33. [CrossRef]

8. Oktay, K.; Harvey, B.E.; Partridge, A.H.; Quinn, G.P.; Reinecke, J.; Taylor, H.S.; Wallace, W.H.; Wang, E.T.; Loren, A.W. Fertility preservation in patients with cancer: ASCO clinical practice guideline update. J. Clin. Oncol. 2018, 36, 1994-2001. [CrossRef]

9. Paluch-Shimon, S.; Pagani, O.; Partridge, A.H.; Abulkhair, O.; Cardoso, M.J.; Dent, R.A.; Gelmon, K.; Gentilini, O.; Harbeck, N.; Margulies, A.; et al. ESO-ESMO 3rd international consensus guidelines for breast cancer in young women (BCY3). Breast 2017, 35, 203-217. [CrossRef]

10. Lambertini, M.; Horicks, F.; Del Mastro, L.; Partridge, A.H.; Demeestere, I. Ovarian protection with gonadotropin-releasing hormone agonists during chemotherapy in cancer patients: From biological evidence to clinical application. Cancer Treat. Rev. 2019, 72, 65-77. [CrossRef]

11. Lambertini, M.; Moore, H.C.F.; Leonard, R.C.F.; Loibl, S.; Munster, P.; Bruzzone, M.; Boni, L.; Unger, J.M.; Anderson, R.A.; Mehta, K.; et al. Gonadotropin-releasing hormone agonists during chemotherapy for preservation of ovarian function and fertility in premenopausal patients with early breast cancer: A systematic review and meta-analysis of individual patient-level data. J. Clin. Oncol. 2018, 36, 1981-1990. [CrossRef] [PubMed] 
12. Demeestere, I.; Brice, P.; Peccatori, F.A.; Kentos, A.; Dupuis, J.; Zachee, P.; Casasnovas, O.; Van Den Neste, E.; Dechene, J.; De Maertelaer, V.; et al. No Evidence for the Benefit of Gonadotropin-Releasing Hormone Agonist in Preserving Ovarian Function and Fertility in Lymphoma Survivors Treated With Chemotherapy: Final Long-Term Report of a Prospective Randomized Trial. J. Clin. Oncol. 2016, 34, 2568-2574. [CrossRef] [PubMed]

13. Senra, J.C.; Roque, M.; Talim, M.C.T.; Reis, F.M.; Tavares, R.L.C. Gonadotropin-releasing hormone agonists for ovarian protection during cancer chemotherapy: Systematic review and meta-analysis. Ultrasound Obstet. Gynecol. 2018, 51, 77-86. [CrossRef] [PubMed]

14. Lambertini, M.; Ceppi, M.; Poggio, F.; Peccatori, F.A.; Azim, H.A.; Ugolini, D.; Pronzato, P.; Loibl, S.; Moore, H.C.; Partridge, A.H.; et al. Ovarian suppression using luteinizing hormone-releasing hormone agonists during chemotherapy to preserve ovarian function and fertility of breast cancer patients: A meta-analysis of randomized studies. Ann. Oncol. 2015, 26, 2408-2419. [CrossRef] [PubMed]

15. Munhoz, R.R.; Pereira, A.A.L.; Sasse, A.D.; Hoff, P.M.; Traina, T.A.; Hudis, C.A.; Marques, R.J. Gonadotropin-releasing hormone agonists for ovarian function preservation in premenopausal women undergoing chemotherapy for early-stage breast cancer: A systematic review and meta-analysis. JAMA Oncol. 2016, 2, 65-73. [CrossRef] [PubMed]

16. Bai, F.; Lu, Y.; Wu, K.; Chen, Q.; Ding, L.; Ge, M.; Weng, Z. Protecting effects of gonadotropin releasing hormone agonist on chemotherapy-induced ovarian damage in premenopausal breast cancer patients: A systematic review and meta-analysis. Breast Care 2017, 12, 48-52. [CrossRef]

17. Danforth, D.R.; Arbogast, L.K.; Friedman, C.I. Acute depletion of murine primordial follicle reserve by gonadotropin-releasing hormone antagonists. Fertil. Steril. 2005, 83, 1333-1338. [CrossRef]

18. Kanter, M.; Sapmaz-Metin, M.; Serez, B. Effects of GnRHa on early embryonic development in mice receiving cyclophosphamide. Arch. Gynecol. Obstet. 2016, 293, 203-209. [CrossRef]

19. Meirow, D.; Assad, G.; Dor, J.; Rabinovici, J. The GnRH antagonist cetrorelix reduces cyclophosphamide-induced ovarian follicular destruction in mice. Hum. Reprod. 2004, 19, 1294-1299. [CrossRef]

20. Matsuo, G.; Ushijima, K.; Shinagawa, A.; Takahashi, S.; Fujiyoshi, N.; Takemoto, S.; Terada, A.; Fukui, A.; Kamura, T. GnRH agonist acts as ovarian protection in chemotherapy induced gonadotoxicity: An experiment using a rat model. Kurume Med. J. 2007, 54, 25-29. [CrossRef]

21. Zhang, Y.; Ding, J.X.; Tao, X.; Lu, Z.Y.; Wang, J.J.; Feng, W.W.; Hua, K.Q. Goserelin can inhibit ovarian cancer proliferation and simultaneously protect ovarian function from cisplatin: An in vitro and in vivo study. J. Chemother. 2013, 25, 96-103. [CrossRef] [PubMed]

22. Ataya, K.M.; McKanna, J.A.; Weintraub, A.M.; Clark, M.R.; LeMaire, W.J. A luteinizing hormone-releasing hormone agonist for the prevention of chemotherapy-induced ovarian follicular loss in rats. Cancer Res. 1985, 45, 3651-3656. [PubMed]

23. Ataya, K.M.; Palmer, K.C.; Blacker, C.M.; Moghissi, K.S.; Mohammad, S.H. Inhibition of rat ovarian $[3 \mathrm{H}]$ thymidine uptake by luteinizing hormone-releasing hormone agonists: A possible mechanism for preventing damage by cytotoxic agents. Cancer Res. 1988, 48, 7252-7256. [PubMed]

24. Bokser, L.; Szende, B.; Schally, A.V. Protective effects of D-Trp6-luteinising hormone-releasing hormone microcapsules against cyclophosphamideinduced gonadotoxicity in female rats. Br. J. Cancer 1990, 61, 861-865. [CrossRef]

25. Li, X.; Kang, X.; Deng, Q.; Cai, J.; Wang, Z. Combination of a GnRH agonist with an antagonist prevents flare-up effects and protects primordial ovarian follicles in the rat ovary from cisplatin-induced toxicity: A controlled experimental animal study. Reprod. Biol. Endocrinol. 2013, 11, 16. [CrossRef]

26. Horicks, F.; Van Den Steen, G.; Houben, S.; Englert, Y.; Demeestere, I. Folliculogenesis Is Not Fully Inhibited during GnRH Analogues Treatment in Mice Challenging Their Efficiency to Preserve the Ovarian Reserve during Chemotherapy in This Model. PLoS ONE 2015, 10, e0137164. [CrossRef]

27. Horicks, F.; Van Den Steen, G.; Gervy, C.; Clarke, H.J.; Demeestere, I. Both in vivo FSH depletion and follicular exposure to Gonadotrophin-releasing hormone analogues in vitro are not effective to prevent follicular depletion during chemotherapy in mice. Mol. Hum. Reprod. 2018, 24, 221-232. [CrossRef]

28. Detti, L.; Uhlmann, R.A.; Zhang, J.; Diamond, M.P.; Saed, G.M.; Fletcher, N.M.; Lu, M.; Williams, L.J. Goserelin fosters bone elongation but does not prevent ovarian damage in cyclophosphamide-treated prepubertal mice. Fertil. Steril. 2014, 101, 1157:e1-1164:e1. [CrossRef] 
29. Hasky, N.; Uri-Belapolsky, S.; Goldberg, K.; Miller, I.; Grossman, H.; Stemmer, S.M.; Ben-Aharon, I.; Shalgi, R. Gonadotrophin-releasing hormone agonists for fertility preservation: Unraveling the enigma? Hum. Reprod. 2015, 30, 1089-1101. [CrossRef]

30. Ataya, K.; Rao, L.V.; Lawrence, E.; Kimmel, R. Luteinizing hormone-releasing hormone agonist inhibits cyclophosphamide induced ovarian follicular depletion in rhesus monkeys. Biol. Reprod. 1995, 52, 365-372. [CrossRef]

31. Imai, A.; Sugiyama, M.; Furui, T.; Tamaya, T.; Ohno, T. Direct protection by a gonadotropin-releasing hormone analog from doxorubicin-induced granulosa cell damage. Gynecol. Obstet. Investig. 2007, 63, 102-106. [CrossRef]

32. Bildik, G.; Akin, N.; Senbabaoglu, F.; Sahin, G.N.; Karahuseyinoglu, S.; Ince, U.; Taskiran, C.; Selek, U.; Yakin, K.; Guzel, Y.; et al. GnRH agonist leuprolide acetate does not confer any protection against ovarian damage induced by chemotherapy and radiation in vitro. Hum. Reprod. 2015, 30, 2912-2925. [CrossRef]

33. Torrealday, S.; Lalioti, M.D.; Guzeloglu-Kayisli, O.; Seli, E. Characterization of the gonadotropin releasing hormone receptor (GnRHR) expression and activity in the female mouse ovary. Endocrinology 2013, 154, 3877-3887. [CrossRef]

34. Akgul, C.; Moulding, D.A.; Edwards, S.W. Alternative splicing of Bcl-2-related genes: Functional comnseguences and potential therapeutic applications. Cell Mol. Life Sci. 2004, 61, 2189-2199. [CrossRef]

35. Blumenfeld, Z.; von Wolff, M. GnRH-analogues and oral contraceptives for fertility preservation in women during chemotherapy. Hum. Reprod. Update 2008, 14, 543-552. [CrossRef]

36. Blumenfeld, Z. How to preserve fertility in young women exposed to chemotherapy? The role of GnRH agonist cotreatment in addition to cryopreservation of embrya, oocytes, or ovaries. Oncologist 2007, 12, 1044-1054. [CrossRef]

37. Poggio, F.; Lambertini, M.; Bighin, C.; Conte, B.; Blondeaux, E.; D’Alonzo, A.; Dellepiane, C.; Buzzati, G.; Molinelli, C.; Boccardo, F.; et al. Potential mechanisms of ovarian protection with gonadotropin-releasing hormone agonist in breast cancer patients: A review. Clin. Med. Insights Reprod. Health 2019, 13, 1179558119864584. [CrossRef]

38. Ozcelik, B.; Turkyilmaz, C.; Ozgun, M.T.; Serin, I.S.; Batukan, C.; Ozdamar, S.; Ozturk, A. Prevention of paclitaxel and cisplatin induced ovarian damage in rats by a gonadotropin-releasing hormone agonist. Fertil. Steril. 2010, 93, 1609-1614. [CrossRef]

39. Tan, S.J.; Yeh, Y.C.; Shang, W.J.; Wu, G.J.; Liu, J.Y.; Chen, C.H. Protective effect of a gonadotropin-releasing hormone analogue on chemotherapeutic agent-induced ovarian gonadotoxicity: A mouse model. Eur. J. Obstet. Gynecol. Reprod. Biol. 2010, 149, 182-185. [CrossRef]

40. Lin, Q.Y.; Wang, Y.F.; Weng, H.N.; Sheng, X.J.; Jiang, Q.P.; Yang, Z.Y. Influence of gonadotropin-releasing hormone agonist on the effect of chemotherapy upon ovarian cancer and the prevention of chemotherapy-induced ovarian damage: An experimental study with nu/nu athymic mice. J. Zhejiang Univ. Sci. B 2012, 13, 894-903. [CrossRef]

41. Kishk, E.A.; Mohammed Ali, M.H. Effect of a gonadotropin-releasing hormone analogue on cyclophosphamide-induced ovarian toxicity in adult mice. Arch. Gynecol. Obstet. 2013, 287, 1023-1029. [CrossRef]

42. Park, I.; Lee, S.; Ryu, K.J.; Min, K.J.; Hong, J.H.; Song, J.Y.; Lee, J.K.; Lee, N.W. A gonadotropin-releasing hormone agonist for the prevention of docetaxel-induced gonadal damage. J. Obstet. Gynaecol. 2017, 37, 783-789. [CrossRef]

43. Grundker, C.; Schulz, K.; Gunthert, A.; Emons, G. Luteinizing hormone releasing hormone induced nuclear factor kappaB activation and inhibits apoptosis in ovarian cancer cells. J. Clin. Endocrinol. Metab. 2000, 85, 3810-3820. [CrossRef]

44. Carabatsos, M.J.; Sellitto, C.; Goodenough, D.A.; Albertini, D.F. Oocyte-granulosa cell heterologous gap junctions are required for the coordination of nuclear and cytoplasmic meiotic competence. Dev. Biol. 2000, 226, 167-179. [CrossRef]

45. Gilchrist, R.B.; Lane, M.; Thompson, J.G. Oocyte-secreted factors: Regulators of cumulus cell function and oocyte quality. Hum. Reprod. Update 2008, 14, 159-177. [CrossRef]

46. Fischer, B.; Bavister, B.D. Oxygen tension in the oviduct and uterus of rhesus monkeys, hamsters and rabbits. J. Reprod. Fertil. 1993, 99, 673-679. [CrossRef] 
47. Catt, J.W.; Henman, M. Toxic effects of oxygen on human embryo development. Hum. Reprod. 2000, 15, 199-206. [CrossRef]

48. Elmore, S. Apoptosis: A Review of Programmed Cell Death. Toxicol. Pathol. 2007, 35, 495-516. [CrossRef]

49. Locksley, R.M.; Killeen, N.; Lenardo, M.J. The TNF and TNF receptor superfamilies: Integrating mammalian biology. Cell 2001, 104, 487-501. [CrossRef]

50. Cory, S.; Adams, J.M. The Bcl2 family: Regulators of the cellular life-or-death switch. Nat. Rev. Cancer 2002, 2, 647-656. [CrossRef]

51. Choi, J.H.; Gilks, C.B.; Auersperg, N.; Leung, P.C. Immunolocalization of gonadotropin-releasing hormone (GnRH)-I, GnRH-II, and type I GnRH receptor during follicular development in the human ovary. J. Clin. Endocrinol. Metab. 2006, 91, 4562-4570. [CrossRef]

52. Lu, S.C. Glutathione synthesis. Biochim. Biophys. Acta 2013, 1830, 3143-3153. [CrossRef]

53. Singh, S.; Khan, A.R.; Gupta, A.K. Role of glutathione in cancer pathophysiology and therapeutic interventions. J. Exp. Ther. Oncol. 2012, 9, 303-316.

54. Gurtoo, H.L.; Hipkens, J.H.; Sharma, S.D. Role of glutathione in the metabolism-dependent toxicity and chemotherapy of cyclophosphamide. Cancer Res. 1981, 41, 3584-3591.

55. Del Mastro, L.; Boni, L.; Michelotti, A.; Gamucci, T.; Olmeo, N.; Gori, S.; Giordano, M.; Garrone, O.; Pronzato, P.; Bighin, C.; et al. Effect of the gonadotropin-releasing hormone analogue triptorelin on the occurrence of chemotherapy-induced early menopause in premenopausal women with breast cancer: A randomized trial. JAMA 2011, 306, 269-276. [CrossRef]

56. Liang, L.; Dunn, J.P.; Chen, S.; Tsai, M.S.; Hornburg, D.; Newmann, S.; Chung, P.; Avina, M.; Leng, Y.; Holman, R.; et al. Smart Diaphragm Study: Multi-omics profiling and cervical device measurements during pregnancy. AJOG 2019, 220, S649. [CrossRef]

57. Minde, D.P.; Dunker, A.K.; Lilley, K.S. Time, space, and disorder in the expanding proteome universe. Proteomics 2017, 17, 7. [CrossRef]

58. La Marca, A.; Spada, E.; Grisendi, V.; Argento, C.; Papaleo, E.; Milani, S.; Volpe, A. Normal serum anti-Müllerian hormone levels in the general female population and the relationship with reproductive history. Eur. J. Obstet. Gynecol. Reprod. Biol. 2012, 163, 180-184. [CrossRef]

59. Stigliani, S.; Moretti, S.; Anserini, P.; Casciano, I.; Venturini, P.L.; Scaruffi, P. Storage time does not modify the gene expression profile of cryopreserved human metaphase II oocytes. Hum. Reprod. 2015, 30, 2519-2526. [CrossRef]

60. Rienzi, L.; Balaban, B.; Ebner, T.; Mandelbaum, J. The oocyte. Hum. Reprod. 2012, 27, i2-i21. [CrossRef]

61. Livak, K.J.; Schmittgen, T.D. Analysis of relative gene expression data using real-time quantitative PCR and the 2(-Delta Delta C(T)) method. Methods 2001, 25, 402-408. [CrossRef]

62. Santonocito, M.; Guglielmino, M.R.; Vento, M.; Ragusa, M.; Barbagallo, D.; Borzì, P.; Casciano, I.; Scollo, P.; Romani, M.; Tatone, C.; et al. The apoptotic transcriptome of the human MII oocyte: Characterization and age-related changes. Apoptosis 2013, 18, 201-211. [CrossRef]

(C) 2019 by the authors. Licensee MDPI, Basel, Switzerland. This article is an open access article distributed under the terms and conditions of the Creative Commons Attribution (CC BY) license (http://creativecommons.org/licenses/by/4.0/). 